\title{
An application of adaptation-level theory to transposition responses in a conditional discrimination
}

\author{
JACK CAPEHART AND VICTOR PEASE ${ }^{1}$ \\ UNIVERSITY OF ARIZONA
}

Adult human Ss were required to learn a conditional discrimination in which the choice response of "left" or "right" was made to a series of two lifted-weights stimuli. The correct response to the lighter member $(100 \mathrm{~g})$ was left while right was correct for the heavier $(200 \mathrm{~g})$. Upon completion of the learning of this discrimination $S s$ were presented a test series of seven weights which ranged from 160 to $450 \mathrm{~g}$. The training stimulus of $200 \mathrm{~g}$ was one member of the seven test series. The $A-L$ theory prediction that $S$ s would respond left to weights lighter than the calculated $A-L$, and right to weights heavier than $A-L$, was strongly supported by the data. The prediction that $S s$ would shift their choice response from right to left for the $200 \mathrm{~g}$ weight when it was a member of the test series was also confirmed.

A possible advantage of A-L theory in the area of transposition is continuity with a rather extensive body of data in the area of psychophysics (Helson, 1964). Hebert \& Krantz (1965) suggest that the application of formulations from the above source should lead to quantitative predictions in the field of transposition. The present study represents an attempt to apply one of Helson's (1947) formulas that was developed in psychophysical experiments with lifted weights to data obtained in a transposition situation.

The situation was, in effect, what Spence (1952) has called a conditional or successive discrimination. In this kind of problem, stimuli are presented singly or successively, and a choice response is learned to each stimulus. The situation is rather analogous to the method of single stimuli or absolute judgment in psychophysical scaling.

In the present study it was assumed that $S$ learns a left choice to a weight below (lighter than) A-L and a right choice to a weight above (heavier than) A-L. Upon completion of training, if a test series is presented in such a way as to shift A-L above the heavier weight (i.e., a test series in which the heavier weight is relatively light) then a corresponding transposition of response to the heavier weight should occur.

Also, if decision time or latency of the choice response is obtained for each response, an additional check on the locus of the A-L may be obtained. Since uncertainty or ambiguity of response is said to increase as stimuli approach A-L, the point of longest latency or decision time should be at or near A-L. As stimuli become increasingly distant from $A-L$, latency should diminish.

\section{Method}

Apparatus. An apparatus was constructed whereby S lifted each weight by pulling a string down to a specified mark. The string ran over two ball-bearing pulleys, one of which extended in front of a screen which prevented $\mathrm{S}$ a view of the weight to belifted. One end of the string was attached to an aluminum platform on which the various weights were placed. The platform rested on a microswitch which was wired "normally open" so that when the weight was lifted the circuit was closed. The closed circuit started a Hewlett-Packard Electronic Counter (Model B). A foot switch was released when $S$ had made his discrimination of decision. This opened the circuit and stopped the counter. The weights were made by filling identical jars with metal shot and wax.

Subjects and Procedure. Ss were four undergraduate male students from the University of Arizona. All Ss received the following instructions: "This is a problem in discrimination learning. Your task is to correctly choose one of two responses for a series of weights which will be presented to you. The responses you should use are 'left' and 'right.' That is, after you lift each weight you will say 'left' or 'right.' If your choice is correct I will say 'correct.' If your choice is incorrect I will say 'wrong.' At the moment you make your choice of 'left' or 'right,' release the foot switch and then respond verbally." The two training series weights of 100 and $200 \mathrm{~g}$ were presented to each $\mathrm{S}$ in random order. The correct response for the weight above A-L $(200 \mathrm{~g})$ was "right." "Left" was correct for the weight lighter than A-L $(100 \mathrm{~g})$. The Ss were trained until a criterion of 10 consecutive correct choices was achieved. $S$ was informed prior to the presentation of the first weight that after he had learned the discrimination he would no longer be told whether or not he was correct.

After $\mathrm{S}$ met the criterion of 10 consecutive correct choices, a series of seven test weights was presented. These weights were: $160,200,250,300,350,400$, and $450 \mathrm{~g}$. Each weight was presented five times to all Ss in the same random sequence. $S$ continued to respond "left" or "right" to each of the test weights. During this period, however, he was not informed as to the correctness of his choices. The Ss' choices and decision times were recorded during the training and test sessions.

The theoretical or calculated A-L of the seven test 
Table 1. Proportions of right responses to the seven test series weights.

\begin{tabular}{cc}
$\begin{array}{c}\text { Weight } \\
(\mathrm{g})\end{array}$ & $\begin{array}{c}\text { Proportion of } \\
\text { right response }\end{array}$ \\
\hline 160 & .00 \\
200 & .15 \\
250 & .60 \\
300 & .80 \\
350 & .95 \\
400 & 1.00 \\
450 & .95 \\
\hline
\end{tabular}

series weights was 248.35 g. The A-L was calculated with Helson's (1947) formula for lifted weights in the method of single stimuli. In this formula, $\log (\mathrm{AL}+$ $0.75 \mathrm{~d})=\Sigma \log \mathrm{X} / \mathrm{n}$.

\section{Resulis and Discussion}

The data which were basic for the test of the transposition or response shift hypothesis were the responses of Ss to the $200 \mathrm{~g}$ weight during its presentation as a member of the test series. According to the A-L prediction, the responses of Ss to this weight should shift from the training "right" response to a "left" response during test.

Table 1, which shows the proportion of "right" responses to each of the seven test weights, indicates that the above prediction was sustained. Only three of the 20

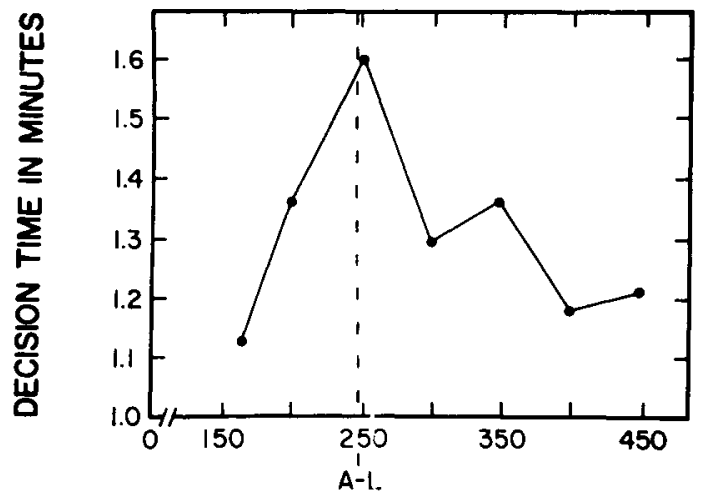

\section{WEIGHT IN GRAMS}

Fig. 1. Decision time as a function of test series weight. responses to the $200 \mathrm{~g}$ weight were "rights." Analysis of variance of the proportion of right responses to the test weights indicated highly significant differences $(F=67.09, d f=6 / 18, p<.001)$. A one degree of freedom test comparing the $200 \mathrm{~g}$ weight with all weights above A-L $(250,300,350,400$, and 450$)$ also gave a significant difference $(F=153.05, \mathrm{df}=1 / 18, \mathrm{p}<.001)$.

Responses to the remaining test stimulus weights were also consistent with A-L theory. The "left" and "right" responses were approximately equal for the weight $(250 \mathrm{~g})$ nearest $\mathrm{A}-\mathrm{L}$, responses to the four remaining heavier weights were predominantly "right" which is what would be expected if Shas learned to respond right to stimuli heavier that $\mathrm{A}-\mathrm{L}$. All responses to $160 \mathrm{~g}$ were "left" responses, again consistent with an A-L prediction.

Decision times were obtained as an additional check on the location of the A-L. Again the obtained results are consistent with the theoretical A-L. As Fig. 1 shows, the decision time for the $250 \mathrm{~g}$ weight was the longest. This weight is very near the theoretical or calculated A-L of 248.35. The points on the graph represent the average decision time for all subjects over the five presentations of each of the test series weights. The plot also indicates a general tendency for decision time to decrease as a series weight becomes increasingly distant from the calculated A-L. Analysis of variance of the data showed reliable differences in decision time means as a function of test series weights $(F=2.90$, $d f=6 / 18, p<.05$ ). A trend analysis revealed a significant quadratic component $(F=4.52, \mathrm{df}=1 / 18, \mathrm{p}<.05)$ in the trend of the decision time means. This curvilinear trend is what would be expected on the basis of A-L theory.

References

HEBERT, J. A., \& KRANTZ, D. L. Transposition: a reevaluation. Psychol. Bull., 1965, 63, 244-257.

HELSON, H. Adaptation level as frame of reference for prediction of psychophysical data. Amer. J. Psychol., 1947, 60, 1-29.

HELSON, H. Adaptation-level theory. New York: Harper and Row, 1964.

SPENCE, K. W. The nature of the response in discrimination learning. Psychol. Rev., 1952, 59, 89-93.

Note

1. Now at St. Lawrence University, Canton, New York. 